\title{
Status of English language teaching in secondary level under different school interventions
}

\author{
Deepika Adhikari \\ Vidyasagar College of Education, Phansidewa, India
}

\begin{abstract}
Language is the primary medium of communication and expression of thoughts and ideas. In India, there are two official languages- Hindi and English. English has been occupying a dominant position since independence. There have been serious attempts to integrate English language in the school curriculum since 1980s. In the schools of West Bengal, English is taught either as a first language or second language. The present study intends to find the status of teaching English language in the secondary schools of Siliguri (West Bengal) where the schools with three different boards, ICSE, CBSE and state boards are chosen. The sample consisted of 50 teachers and 50 students from a total of 25 schools. A survey method and observation inventory was used for collection of data. The conclusion is that English language teachers need to abreast themselves with the latest developments in the context of language teaching. The co-operation from the school, teachers, parents and students yield fruitful results in improving the status of English language teaching.
\end{abstract}

Keywords: English language teaching, Status of English, ICSE board, CBSE board, state board.

\section{Introduction}

English is one of the foremost international languages in the world. English in India is used not only for communicating with the outside world, but also for inter-state and intra-state communication. It symbolizes in Indians' minds, better education, better culture and higher intellect. After Hindi, it is the most commonly spoken language in India and probably the most read and written language (Vijayalaxmi \& Babu,
2014). The importance of English language study has been well articulated in The National Curriculum Framework (2005) in the following words: "English in India is a global language in a multilingual country. A variety and range of Englishteaching situation prevail here owing to the twin factors of teacher proficiency in English and pupils' exposure to English outside schools." English in India is no longer a language of the colonial rulers rather it has become an integral part of the Indian multilingual repertoire. The attitudes of the contemporary Indians towards 
English are significantly more positive than what we for example find in the Constituent Assembly debates of 194649.

English plays an important role in the domains of education, administration, business and political relations, judiciary, industry, etc. and is therefore a passport to social mobility, higher education, and better job opportunities. In urban India, it is very common to see young people code mixing and code switching between English and Indian languages. It is indeed unfortunate that English has so far remained associated with the rich, elite or upper middle class. It should be the effort of the Indian educational system to reach English to every Indian child and to ensure that she/he gains a sufficiently high level of proficiency in it and not suffer discrimination for lack of it. The teaching and learning of English today is characterized by the diversity of schools and linguistic environments, and by systematically pervasive classroom procedures of teaching a textbook for success in an examination.

\section{Position of English in West Bengal}

As per the recommendations of the Kothari Commission (1964-66) the three language formula was developed for the educational load to be fairer to promote national integration and to provide wider language choice in the Indian school curriculum. According to the formula people from non-Hindi areas study their regional language or Hindi, English and another language. Although the formula sounds fine in theory, practically it has proved to be a failure in India as a whole since it has not been followed in practice. Effective learning takes place only when the learner is able to communicate fluently both in writing and speaking and is able to use English for library purposes.

In West Bengal English was abolished completely from the primary stage from 1950 to 1963 . It was again reintroduced from class III in 1964 and continued to be taught as a compulsory second language from class III up to 1983 . But from 1984, the state government again eliminated from the primary stage and introduced it from class VI instead of class III. The abolition of English from the primary stage gave rise to a widespread movement in West Bengal demanding its reintroduction at the primary stage. Therefore, The Ashok Mitra Commission (1992) was set up to ponder over the problem of introducing English at the primary stage and recommended that "the teaching of English in government and governmentaided institutions may commence from class $V^{\prime \prime}$. But the state government did not pay heed to it. After 14 years West Bengal government bowed down to the popular demand and appointed a oneman committee named Pabitra Sarkar Committee (1998) in order to decide the class at which English should be introduced. Thus from 1999 English was taught from class II. Nevertheless, the Mukhopadhyay Committee (2003) in its report again recommended introducing English from class V. However, on the pretext of the globalization, the West Bengal government reintroduced English in Class-I in all schools in 2004. Thus, the circle became full within two decades. And the most pleasing fact is that the present Government has made 
a proposal to set up English medium Primary Schools to recognise the importance of English and to make an initiative to change the existing scenario of English education in West Bengal. Thus, the teaching of English as a second language continues up to class XII. There is a provision for third language (a classical language/ a modern Indian language/ a foreign language) which is taught compulsorily in classes VII and VIII.

The repeated changing status of the position of English language and its teaching prompted the researcher to ponder over the current status of English teaching in the secondary schools of West Bengal. The current study aims to study the present status of teaching English language in the context of secondary schools in West Bengal. The study aims to highlight the problems, if any, faced by the teachers in teaching English language and to recommend solutions to overcome the difficulty faced in the English language classrooms.

\section{Review of literature}

Banerjee (2016) found that in the schools of West Bengal not much importance is given to English as it is taught as a second language. The teachers also are not competent enough to teach the subject properly. Salma and Nehal (2017) observed that in the madrasas of West Bengal only reading and writing skills are focused in textbook and it does not have any single activity on listening and speaking skills. Although it has been mentioned in syllabus and teachers are guided to fulfil all these competencies but in classroom conversational skill does not exist. Even the classroom is mainly teacher-oriented; students only seem as listeners. Saranya (2018) suggested the need for the teachers to equip themselves with the latest technology and gain mastery over English to improve their all the four language skills.

Malarvizh (2018) remarks when English is taught as a second language, the teachers tend to overlook the errors made by the students. She recommended the need to use English aptly in an everyday basis. Meganathan (2011) studied that in the states of India, some schools offer English as the first language while others offer it as the second language. Most schools in the country do not have the facilities and proficient teachers needed to cater to the demand. Arocena and Popma (2014) in their report discovered that secondary school students in the Basque Country and in Friesland do not use the foreign language (English) very extensively, either at school or outside. English is learnt as a foreign language only at school. Anyiendah(2017) found that limited classroom language opportunity for the learners to practice the language has stunted their exposure to learning English. In upper primary, the learners' only opportunity to use English language is limited to the daily 35-min English lesson. Khan, Ahmed and Munir (2013) found the problem that the teachers in Provincial government schools were not sufficiently qualified and had not adequate knowledge of teaching methodologies of teaching English.

Hoang (2018) gave a different idea related to his research. He concluded that English teaching has been speeding up since 1990s and those who do not have a 
sufficient competency over the language has developed a feeling of exclusion. Malaynathan (2016) observed that none of the selected schools has any modern aids like audio-visual aid and projector; only the traditional aids, such as blackboard and white chalk, are used. Ahmed (2016) studied that students from English medium school are made more conscious about the smartness, personality and English communication skills, though in vernacular medium school students are far backward in this regard. However, the fact is that 'English' is considered to be the language of 'Status'. So, hear in Secondary Schools of Assam, English is taught as the Second language (L2), First language (L1) being mother tongue. It is disheartening to note that the lack of use of proper English methodology in the classroom, indifference of most of the Head Teachers of the schools in implementing English conversation during the class as well as school activities to enhance the spoken scenario has badly affected English teaching in the Secondary Schools of Assam. The National Council of Education, Research and Training (NCERT) in Syllabus for classes at the elementary level suggested to creating socio-cultural contexts, if possible, even outside the classrooms that would encourage children to participate actively in understanding and creating appropriate communicative practices.

\section{Rationale of the study in Siliguri}

English occupies an important place in the school curriculum in the context of development of a nation and making it par with developed nations. In India specifically in Siliguri there are two types of secondary schools- government or governmentaided schools and private schools. The government or governmentaided schools are those schools which are managed directly by the state government or by the local municipalities under the state government; while the private schools are self-financed schools with no financial aid from the government and run entirely by the private firms or organizations. In the government-managed schools, the language English is a second language whereas in non-government schools it is the medium of instruction. Students coming out of state run schools are taught English as a second language which is the reason why students passing out from state run schools are not able to compete with students coming from private schools. Therefore, the poor status of teaching English, ill qualified teachers, ill equipped secondary schools for teaching English language, less weight age given for teaching English, no proper transactional strategies adopted for teaching are the main drawbacks. (Banerjee, 2016). On reviewing the previous researches it was found that no study from Siliguri was taken. Siliguri is now an educational hub where students from the neighbouring states are overflowing in a considerable amount (as per reports derived from http://siliguri.co.in/education. Moreover, no prior studies in relation to different boards (ICSE, CBSE and state board) have been taken up. Thus the current study aims to address these gaps which give rise to the following research questions:

1. Are English teachers of the secondary level well equipped and well qualified to teach in the class? 
2. How much weight age is given to English language teaching in the secondary school timetable?

3. What types of transactional strategies are used for teaching English in schools with different boards?

4. What are the challenges faced by the teachers and learners in language teaching learning?

\section{Objectives of the study}

Following are the primary objectives involved in the study:

- To study the status of teaching English at the secondary level in the schools of Siliguri.

- To examine the effect of teachers' qualification, medium of instruction and type of examination boards in teaching English.

- $\quad$ To study the problems faced by the teachers in teaching English in the secondary schools.

\section{Scope and delimitation of the study}

A vast extensive research study has been undertaken to analyse the status of teaching English at secondary schools of North Bengal but due to time, resources and other constraints the investigator has resorted the present study to the secondary schools situated in the main town of Siliguri. The present study will be limited to:

i. 25 schools of Siliguri which include 10 ICSE board schools, 10 State board schools and 5 CBSE board schools. ii. 50 students studying English in ninth grade have been taken as samples.

iii. 50 teachers teaching English have been selected as samples. iv.25 observations of ninth grade classroom teaching have been done.

v. The study analyses the status of teaching English language with regard to qualification of teachers, medium of instruction, type of school boards, weight age given to English in timetable, availability of resources and problems faced by teachers and students in teaching and learning English in secondary schools.

\section{Operational definitions}

English language teaching- English language teaching refers to the strategies adopted in schools for teaching English language by professionally skilled English teachers for transacting the curriculum.

Status-Status here refers to the position and availability of facilities for academic support and level of performance in relation to the appropriate standards in schools at present.

Secondary Schools-Secondary schools refer to the students reading in ninth grade in schools where English is taught either as a first language or a second language.

School Interventions-School interventions here refer to the medium of instruction of the schools, board of examinations and the types of schools. Medium of instruction refers to English and Bengali 
medium schools, school board of examinations refers to CBSE board, ICSE board and state board of examinations and types of schools refer to government and private schools.

\section{Research methodology}

\section{Method}

The present study uses a mixed method research which employs both qualitative and quantitative methods. For data collection, survey and classroom observation technique (Suman, 2013) have been employed.

\section{Sample}

The details of the population and sample are shown in the given table:

Table: 1. List of the total number of schools in Siliguri Municipal Area

\begin{tabular}{|l|c|c|}
\hline $\begin{array}{c}\text { Type of school } \\
\text { boards }\end{array}$ & $\begin{array}{c}\text { Total no. of } \\
\text { schools }\end{array}$ & $\begin{array}{c}\text { No. of schools } \\
\text { selected }\end{array}$ \\
\hline I.C.S.E & 53 & 10 \\
\hline C.B.S.E. & 35 & 5 \\
\hline STATE BOARD & 104 & 10 \\
\hline
\end{tabular}

Table: 2. Details of the Sample

\begin{tabular}{|l|c|c|c|} 
& Male & Female & Total \\
\hline Students & 17 & 33 & 50 \\
\hline Teachers & 13 & 37 & 50 \\
\hline $\begin{array}{l}\text { Observation schedule one } \\
\text { from each school } \\
(\mathbf{1 x 2 5 = 2 5 )}\end{array}$ & 25 \\
\hline
\end{tabular}

\section{Tools used}

Since this was a survey type of research, the investigator selected questionnaire suitable for the study, as it required some factual information from a large number of teachers and students as respondents within a short span of time. A standardized tool developed by Santosh Suman (2013) was used for collecting data. The following tools were used for collecting data:

A. Questionnaire for English Language Teachers

B. Questionnaire for English Language Students

C. Classroom Observation Schedule cum Inventory

\section{Questionnaire for English language teachers}

This questionnaire consisted of background information of teachers along with the following items: Training programme attended by them, transactional strategies adopted in classroom, remedial teaching programme adopted, feedback mechanism and teachers' personal reaction for teaching English in class, steps taken by the teachers for the improvement in teaching language.

\section{Questionnaire for English language students}

It included items covering the interest of the learners to read English, hours devoted by them, liking for studies, performance of assignments and clarification of doubts from the teachers. 


\section{Classroom observation schedule cum inventory}

This questionnaire consisted of items in respect of classroom observation of teaching of English. It has two sections: Part A consists of general information regarding the school and Part B contains the classroom transaction process which consists of conducive classroom atmosphere, availability of instructional materials in the class, media support and the transactional strategy adopted by the teacher and response by the students there of.

\section{Data analysis}

The data have been analysed qualitatively as well as quantitatively. All the data using the aforesaid tools were measured in tabular and graphical figure to illustrate the status of teaching English language at secondary schools in different types of schools in Siliguri. The study had three objectives, the first dealing with the status of teaching English language; the second focused on the effect of teacher's qualification, medium of instruction and type of examination boards in teaching English while the third focused on the problems faced by the teachers in teaching English. Athematic framework has been used to analyse the data the themes for which emerge from the research objectives.
Fig.1. With respect to the first objective of the study i.e., to examine the status of teaching

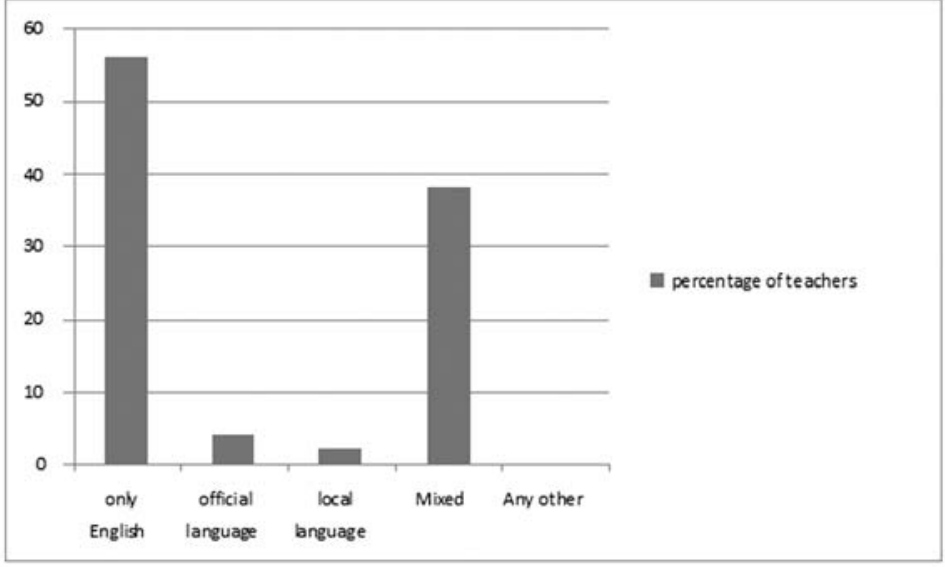

English in thesecondary schools the analysis is presented below.

It was observed that out of 50 teachers, 28 , i.e., $56 \%$ teachers were using English while 19, i.e., $38 \%$ teachers used mixed method i.e., both English and mother tongue laying more emphasis on grammar translation method. There were 2 teachers who laid more emphasis on official language while 1 teacher made use of local language because of poor learning ability of children.

\section{Fig.2. Teacher's activities to improve learner's learning}

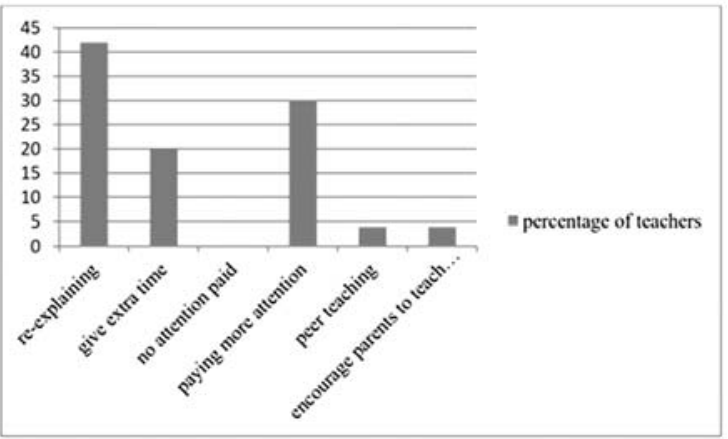


As shown from the above figure regarding teacher's activities to improve learner's learning, out of 50 teachers 21 of them, i.e., $42 \%$ teachers made a point to explain more than once to the ones who have not understood; $20 \%$, i.e., 10 teachers gave extra time to recapitulate the ideas; $30 \%$, i.e., 15 teachers paid more attention by helping the slow learners; while only 4 of them, i.e., $8 \%$ teachers focused on peer teaching and encouraged parents to help out the students at home.

Fig.3. Teaching learning resources available in the schools and used by the teacher

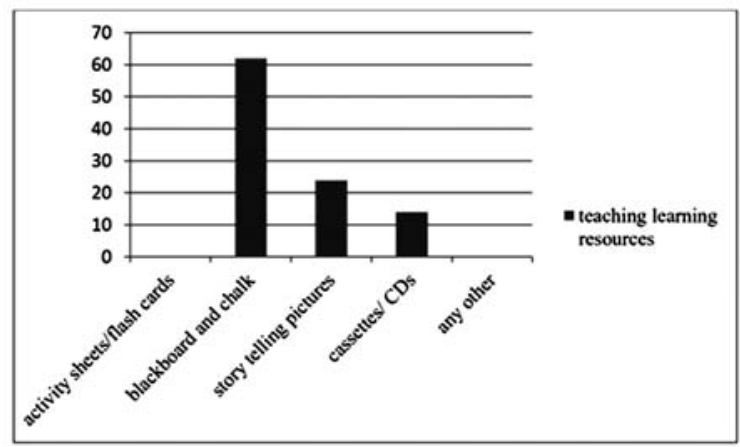

In all the I.C.S.E. schools and C.B.S.E. schools the above resources were available. In case of state boards schools only a few school availed the resources. As seen from the above table none of the teachers made use of activity sheets or flash cards while 31 teachers i.e., $62 \%$ teachers used blackboard and chalk. Story telling pictures and CDs were utilized by only 12 teachers (24\%) and 7 teachers $(14 \%)$ respectively. Interestingly when it was asked from the teachers regarding any innovations of any teaching aids from their own side, answer was blank. No any other teaching aids were innovated or used by any of the teachers.
With respect to objectives in relation to type of examination boards

Taking into consideration the I.C.S.E. board of examination following analysis has been made:

\section{Fig.4. Distribution of periods in different I.C.S.E. schools (Class IX)}

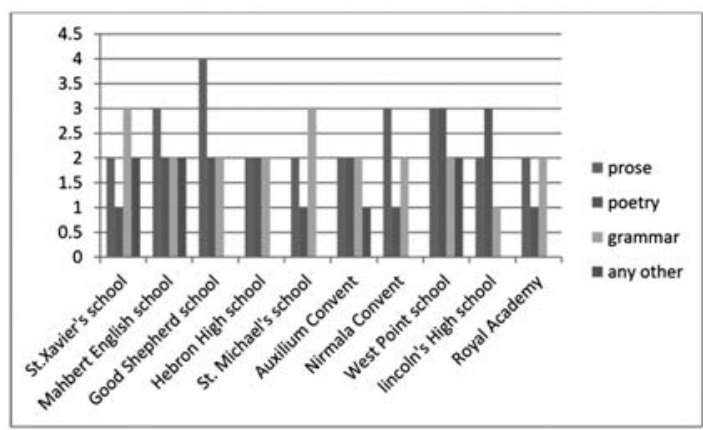

The data show that all the I.C.S.E. schools devoted five or more periods for teaching of English. West Point school allotted 10 periods weekly for teaching of English with Royal Academy being the only school with 5 English classes in a week. English was taught as a first language in all these schools. All the three sections- prose, poetry and grammar were given due importance. However, it is noteworthy to mention that three schools devoted extra time for project work and development of oral and aural skills among students. The time allotted for teaching of subject was 45 minutes with lots of activity work. 
Fig.5. Distribution of periods in different C.B.S.E. schools (Class IX)

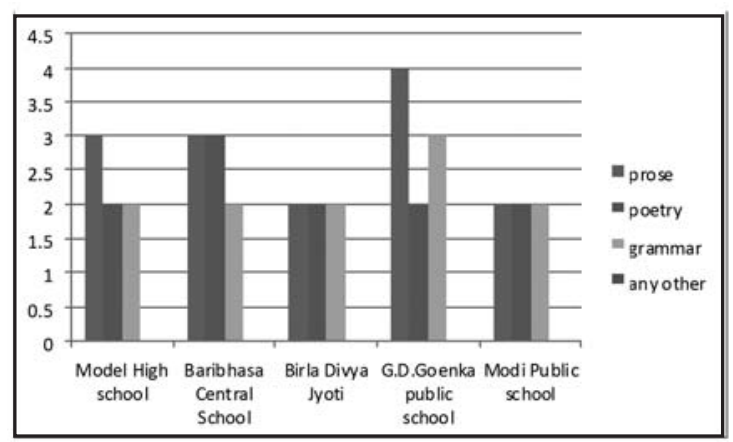

The above figure implies that almost equal weight age was given to English in all the C.B.S.E. schools and equal priority was paid to three different sections- prose, poetry and grammar. The subject was taught for 45 minutes and is taught both at the first half and the second half.

Fig.6. Distribution of periods in different state board schools (Class IX)

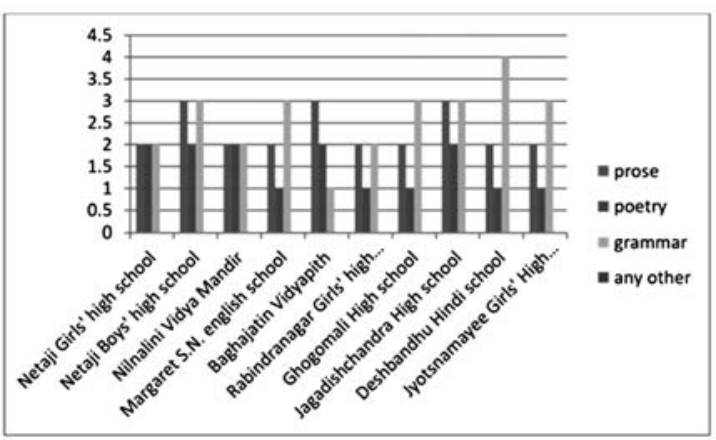

From the above graph it has been made clear that the state boards also devoted more than 5 language classes per week with the exception of Rabindranagar Girls' high school where English was taught only 5 classes per week. English was taught for 40 minutes in these schools and was taught as a second language.

\section{Fig.7.Ambience/Environment of English class in ICSE, CBSE and state board schools}

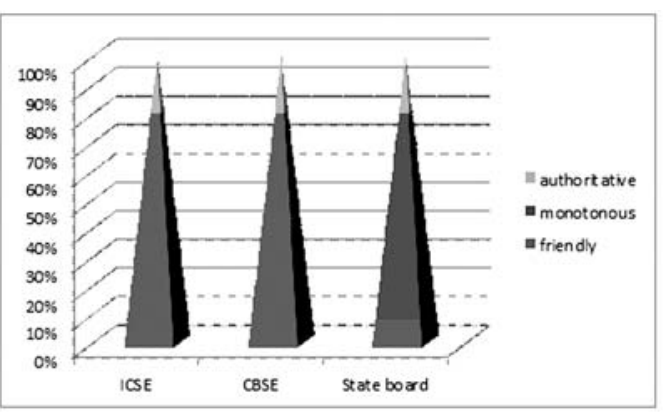

The above figure illustrates that the English learning atmosphere was friendly and cordial in eight I.C.S.E. schools while the atmosphere of two schools i.e., $20 \%$ was authoritarian. However, $80 \%$ of the schools' atmosphere was amicable and a good rapport was established between the teachers and students. It is also evident that the ambience of all the four CBSE sample schools was friendly where the teacher taught relationship was cordial whereas there was only one school where the atmosphere was authoritative and the teacher was strict. While in the state board schools $70 \%$ of the English classroom environment was monotonous and boring because the teachers did not make use of innovative techniques and hardly used English language in the classroom. Only the teachers of 1 school made the environment lively and friendly while the other two schools had an autocratic and authoritarian atmosphere.

As per the objective of the study teachers' qualification has a very important role 
to play in transacting the lesson. The analysis is presented below:

\section{Fig.8. Categorization of Teachers} in school on the basis of their Academic Qualifications

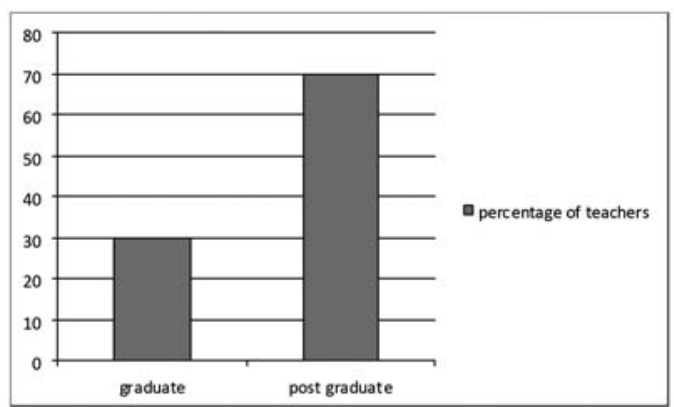

of examination $76 \%$ teachers were trained professionally as they were possessing B.Ed. degree, $12 \%$ teachers were found to have obtained diploma in teacher education while the rest $12 \%$ were untrained. These remaining 6 teachers who were untrained should undergo teachers' training programme to upgrade themselves as professional teachers.

Table 3. Level up to which the teachers have studied English

Fig.8. shows that 15 teachers were graduates and 35 teachers were having Post-Graduate degree. Thus $30 \%$ of teachers were graduates and $70 \%$ of teachers were Post-Graduate. This result reveals that most of teachers were highly qualified than expected and required qualification.

Fig.9. Categorization of teachers on the basis of their professional qualification

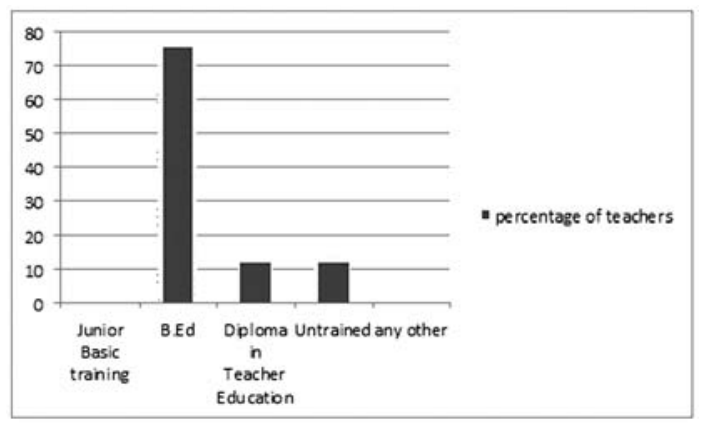

Fig.9. shows that in all the three school boards, i.e., ICSE, CBSE and state boards

\begin{tabular}{|l|l|l|c|c|c|c|}
\hline & Level & XII & $\begin{array}{c}\text { Gradu- } \\
\text { ation }\end{array}$ & P.G. & $\begin{array}{c}\text { Above } \\
\text { P.G. }\end{array}$ & Total \\
\hline $\begin{array}{l}\text { Number of } \\
\text { teachers }\end{array}$ & 0 & 0 & 15 & 30 & 5 & 50 \\
\hline $\begin{array}{l}\text { Percentage } \\
\text { of teachers }\end{array}$ & 0 & 0 & 30.00 & 60.00 & 10.00 & 100 \\
\hline
\end{tabular}

The above figure shows that $60 \%$ teachers were masters in English 30\% teachers were graduates in English while $10 \%$ teachers were holding MPhil in English. None of them had confined their studies up to class X or XII. Since the study focuses on the teaching status of English language in three types of schools- ICSE, CBSE and state board schools the medium of instruction has a prime role to play here. 
Table: 4. Medium of instruction in three types of examination boards
Method of Teaching English Language by the Teachers

\begin{tabular}{|l|c|c|c|c|}
\hline I.C.S.E. & English & $\begin{array}{l}\text { Regional } \\
\text { language }\end{array}$ & $\begin{array}{c}\text { Bilin- } \\
\text { gual }\end{array}$ & $\begin{array}{c}\text { Multil- } \\
\text { ingual }\end{array}$ \\
\hline C.B.S.E. & $\square$ & - & - & - \\
\hline State board & - & - & - & - \\
\hline
\end{tabular}

Majority of the language teachers use either direct method or grammar translation method. The table below gives a vivid idea about the way of teaching English language by the sample teachers.

The above table makes it clear that the medium of instruction in the ICSE schools and the CBSE schools was English. Thus, while explaining the content of English the teachers made use of English language only. But in case of state boards the medium of instruction was either Hindi or

Bengali thus the teacher in the English class made use of both English and the regional language.

The students in the state board schools must be exposed to English language and the teacher must work hard to use English inside and outside the class in order to make the students well versed in the language.

\section{With respect to objectives in relation to the challenges faced during English language teaching}

On studying the problems faced by the teachers in all of the above schools it can be said that the major problem faced by the ICSE schools was lack of teaching materials and that of CBSE schools is teaching a large number of students while the state board teachers were engaged on non-teaching duties like, election, data collection, surveys, sent for trainings, meetings etc.

\section{Fig.10. Method used by teachers for teaching grammar}

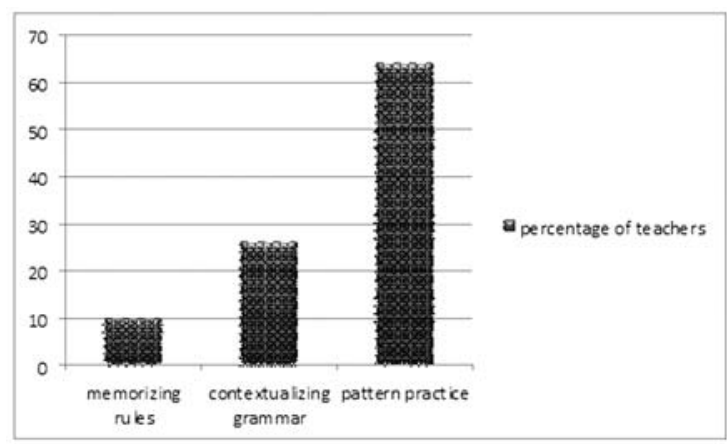

The above graph shows that 5 untrained teachers i.e., $10 \%$ taught grammar by memorizing rules. 32 teachers, i.e., $64 \%$ of them taught by pattern practice while 13 of them i.e., $26 \%$ teachers contextualized grammar and taught by integrating it with the lesson.

\section{Fig.11. Method used by teachers for teaching new words}

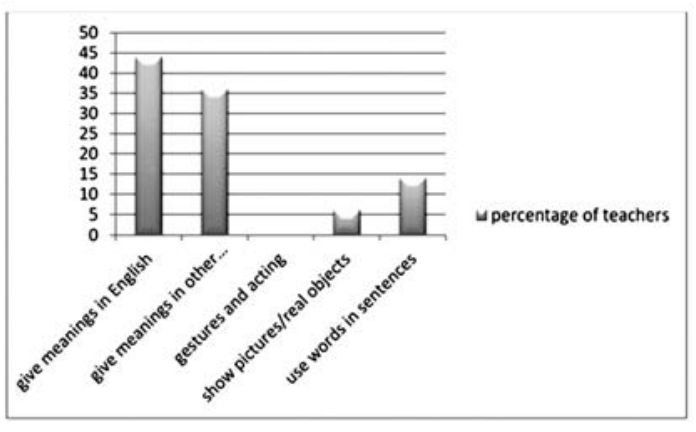


From the above graph it is clear that $44 \%$ teachers taught new words and phrases in English.36\% teachers, i.e., 18 of them helped the students understand new words by giving the meanings of words other than English, i.e., by using grammar translation method. 7 teachers, i.e., $14 \%$ of them used new words in different way and helped the students infer the meaning of words while only 3 of them, i.e., $6 \%$ showed pictures, flash cards to make the students comprehend the meaning of words. Language teachers should engage the students in exposing meaning of new words rather than giving them their meanings directly.

\section{Fig.12. Method of teaching poetry}

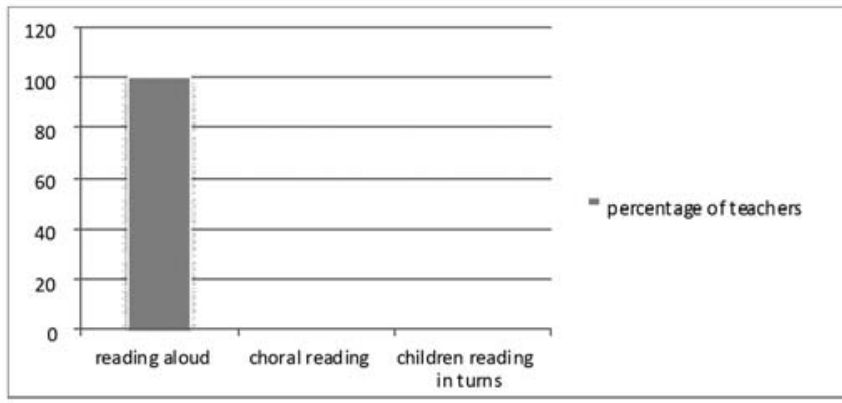

Surprisingly, it was noted that all the teachers taught poetry by reading aloud to the students. After they read aloud only then the students were asked to follow them in chorus. This was no exception to any of the teachers thus the above table makes clear that $100 \%$ teachers followed the proper method of teaching poetry.

\section{Analysis of data with respect to classroom observation}

Classroom observation was carried out in 25 sample schools- 10 ICSE schools, 5
CBSE schools and 10 state board schools. The observation was conducted during teaching learning time as provided in the school time table.

The investigator visited 10 ICSE schools and observed one class of each teacher and found out that English as a first language was taught both at the first half and the second half. The duration of the period was 45 minutes in all the schools. Teachers communicated with the students in English only, no other languages were used besides English. The classrooms were well ventilated and were spacious. Classroom was highly democratic. All the teachers brought text books with them and the students were also seen to have the required text books and note books. The blackboard was neat and was of adequate size. Surprisingly, the libraries of all the 10 schools were well equipped with multimedia, books, handbooks, computers and newspapers. But a few teachers used story telling pictures. Besides, the only teaching aids used by teachers were board and chalk, textbooks and handbooks.

Interestingly, while interacting with the students the teacher frequently asked questions and motivated them to respond who could not answer. The teachers catered to the needs of the children thus making the ambience of the classroom child centric. Various feedback was received from the teachers such as teacher-pupil ratio should be maintained, adequate resource materials to be introduced in the school, class library should be provided for better 
access to the children, language laboratory to be introduced, parents' suggestions to be welcomed, students should be encouraged to develop all the four essential skills- listening, speaking, reading and writing.

The investigator visited 5 CBSE schools and observed one class of each teacher and found out that English was taught as a first language in all the 5 sample schools. The duration of each period was 45 minutes and the subject was taught both at the first half and the second half except in Baribhasa Central school where English is given due importance and is taught only at the first half. The medium of instruction is English in all the 5 sample schools. Teachers were seen to communicate in English both inside and outside the classroom premises. The classrooms were well organized with proper seating arrangement accommodating a large number of students. They were well lit, spacious and well ventilated. All these institutions were privately and independently run by various organizations. The teachers were equipped with required text books and the students were encouraged to maintain the same. The libraries were facilitated with textbooks, reference books, handbooks, computer with internet, cassettes and CDs. The classrooms were equipped with smart boards but none of the teachers were seen to operate the smart board while transacting the lesson. The classroom atmosphere was democratic except G.D. Goenka Public school where the teacher behaved strictly with the students because she was having a problem to handle such a large number of students. The children maintained utter silence and were less interested to participate in the learning process. However, the teachers of other CBSE schools handled the students carefully and the latter were motivated to participate in the classroom interaction. The teachers of all these schools took the pain of using teaching aids making the classroom livelier. At the end of the lesson the teachers were seen summarizing their lesson taught to find out whether the students have understood the content. The suggestions collected from the teachers regarding English language teaching were - more trained language teachers to be recruited. Addition of more sections to maintain the teacher-pupil ratio, teachers to be provided training for use of smart boards, student-friendly atmosphere to be encouraged, frequent parent teacher association to be organized, various literary competitions- debate, extempore, essay writing, to be organized at frequent intervals to make the students well versed in the language.

The investigator visited 10 state board schools and observed one class of each teacher and found out that the medium of instruction in all the state board schools was either Bengali or Hindi thus English was taught as a second language. A proper attention was required towards English language teaching. The duration of teaching was 40 minutes and English was taught both at the first half and the second half. English was not the medium of communication in any of these schools rather regional/state language was given due importance. That is why the teacher was seen to use other language apart from English while transacting the lesson in the classroom. The seating arrangement was well organized but all 
the classrooms were dirty and unhygienic. The condition of the blackboard was lurid hardly visible to the last benchers. Except for Margaret S.N. school all the other schools gave prominence to regional language. Majority of the teachers were trained yet they lacked effective classroom transaction. The teacher hardly asked questions to the students and a very little room was given to students for interaction. Teachers were concerned about completing the syllabus rather than interacting with the students.

Although a good number of resources were available such as models, chart papers and flash cards yet the teachers used black board and chalk and text books. Technology based learning was not implemented. The newly recruited untrained teachers were unable to represent the contents systematically. The teachers were seen to behave indifferently with the students except a few who catered to the needs of the children. Thus the classroom was sometimes friendly and sometimes authoritative. The teachers of Deshbandhu High school and Netaji Girls' high school recapitulated the content for the last ten minutes and gave homework to the students. The library was filled with all the necessary requisites but the teacher seldom used them. No teacher made an effort to communicate in English with the students that is the reason why most of the students showed lack of confidence and less interested in the classroom. Various recommendations which the teachers came up with are- teacher-pupil ratio should be maintained properly. Teachers should not be given non- teaching duties, parental involvement to be encouraged, English atmosphere must be created at home, Govt. must provide practice books to the students, medium of instruction to be changed to English, students to be encouraged to write stories, songs, and various articles on the topics of their interest for developing writing skills and to come at par with the students of other boards.

\section{Results}

In ICSE and CBSE boards English was taught as a first language while in the state boards English was taught as a second language at the secondary level. The performance of the students in state board schools were not up to the mark as compared to the other two board of examinations. English language environment was not seen in state board schools while it was seen in abundance in ICSE and CBSE schools. Parents of the students studying in state board schools were less cooperative than the parents of students studying in ICSE and CBSE schools. Teachers were less interested to use teaching aids in the class. Common teaching aid was blackboard, chalk and text books. No innovations in method of teaching were created by the teachers. Everyone relied on the resource materials provided by the school. There was no difference in the provision of teaching periods for English in different schools under different boards.

\section{Conclusions and recommenda- tions}

In the light of the above study the researcher would like to make a few recommendations that the recruitment of 
teachers should be done on the basis of their academic and professional qualification so that the students' learning of language does not get affected. As the language teachers are not competent (Banerjee, 2016) there is a need to appoint experienced and well qualified teachers to cater to the learning needs of the students. The students of state boards have a high urge to learn the language therefore the teachers should create an English learning ambience both inside and outside the classroom. Classroom library should be established so that the students can develop the habit of reading. Extra periods should be allotted in all the schools for developing the habit of listening, speaking, reading and writing skills or else limited classroom language opportunity for the learners to practice the language will stunt their exposure to learning English (Anyiendah,2017).

The teachers should create a 'constructivist' classroom to develop the power of imagination and creativity among students. The school administration can encourage the teachers to participate in national and local academic activities. They can organize periodical workshops and training programmes for their teachers. Various literary programmes, viz., debate, extempore; speeches, essay writing, poetry writing, recitation, role playing etc. can be organized. An English speaking atmosphere can be created at home to make the students speak fluently. Lastly, the medium of instruction had a very important role to play in effecting desirable changes in behavior of students in learning English language.

\section{References}

Ahmed, M.S. (2016). The English Language Teaching (ELT) in the Secondary Schools in Assam. International Journal of English language, literature and Humanities, 4 (3), 219223.

Anyiendah, M.S. (2017). Challenges Faced by Teachers When Teaching English in Public Primary Schools in Kenya.

Retrieved July 1, 2019 from https://doi.org/10.3389/ feduc.2017.00013

Arocena, E. \& Popma, J. (2014). English language teaching in secondary education and the use of English outside school: A comparison of the Basque Country and Friesland, Mercator European Research centre on multilingualism and Language learning, $1,5-57$.

Banerjee, S. (2016). A Study of Current Status Quo of English as a Second Language in India study done on West Bengal Schools, International Journal of Scientific and Research Publications, 6 (8), 478-483.

Bhatnagar, S. (2014). Modern Indian Education and its problems. R.Lall Book Depot: Meerut, India

Freeman,D. (1989). Teacher Training, Development, and Decision Making: A Model of Teaching and Related Strategies for Language Teacher Education. TESOL Quarterly, 23 (1), 2745.

Gupta, A. (2012). A Handbook of Teaching English. Central library Publishers and book sellers: Kolkata, India 
Hoang, V. (2018). The Current Situation and Issues of the Teaching of English in Vietnam. Retrieved June 21, 2019 from www.researchgate.com

Khan \& et.al (2013).Factors Affecting the Learning of English at Secondary School Level in

Khyber Pakhtunkhwa, Pakistan,International Journal of English Language and Literature Studies, Asian Economic and Social Society, 2 (2), 95101.

Mahanta and Divyagunanada (2018).A Study on the Genesis of English as a Second Language at Lower Primary Level in West Bengal, IJRAR, 5 (3), 14371441.

Malarvizh, K. (2018). Challenges in English Language Teaching as a Second Language in India. Bodhi International Journal of Research in Humanities, Arts and Science, 2 (26), 96-99.

Malaynath (2016). Problems in Teaching English in Secondary Schools in North Tripura District. Retrieved June 14, 2019 from www.languageinindia.com

Meganathan, R. (2011). Language policy in education and the role of English in India: From library language to language of empowerment. Dreams and Realities: Developing Countries and the English Language, Retrieved June 15, 2019 from www.britishcouncil.org

Salma and Nehal (2017). Analyzing the Status of English Language Teaching in Madrasas for Local and Global Employment: Some Evidences from Murshidabad District of West Bengal. IOSR Journal of Humanities And Social Science, 22 (9), 58-62.
Saranya, J. (2018). Challenges in ELT as a Second Language, Bodhi International Journal of Research in Humanities, Arts and Science, 2 (26), 83-87.

NCERT (2014). Syllabus for classes at the elementary level. Retrieved August 13, 2019 from: http:/ / www.ncert.nic.in/ rightside/links/pdf/syllabus/vol1/ 05English \% 20(I-VIII).pdf

Vijayalaxmi and Babu (2014). A Brief History of English Language Teaching in India, International Journal of Scientific and Research Publications, 4 (5), 1-4.

Siliguri.co (2019). Educational Institutes of Siliguri. Retrieved August 14, 2019 from http://siliguri.co.in/education

Contributor: Deepika Adhikari is an Assistant Professor in English and Education in Vidyasagar College of Education, Phansidewa, Darjeeling, West Bengal, India. She hold majors in English (2012) and is a Gold medalist in Education (2017). She has qualified the National Eligibility Test conducted by CBSE, India. She has edited three books and has published papers in various international journals. Her area of interest lies in Language education and Technology. 